\title{
Aplicação e Avaliação do Moodle como Tecnologia Complementar na Capacitação de Professores
}

\author{
Lucas Plautz Prestes ${ }^{1}$ Andreia Solange Bos ${ }^{12}$, Paula R. Castro ${ }^{1}$, Milton Zaro ${ }^{1}$ \\ Michelle Pizzato \\ ${ }^{1}$ Centro Interdisciplinar de Novas Tecnologias na Educação- Universidade Federal do \\ Rio Grande do Sul (UFRGS) \\ CEP - 90040-060- Porto Alegre - RS - Brazil \\ ${ }^{2}$ Instituto Federal do Rio Grande do Sul (IFRS) Porto Alegre - RS - Brazil \\ \{lucas.plautz.prestes, andreia.bos, paula.r.castro\}@gmail.com, zaro@ufrgs \\ .br, michelle.pizzato@poa.ifrs.edu.br
}

\begin{abstract}
From the evolution of EAD in Brazil it can be affirmed that this practice is consolidated in the superior course. The occurrence of this statement, little is related to the basic structure of teaching and application. Therefore, the objective of this study is to carry out the case study in EAD teaching applications, in a way complementary to traditional basic education. The research covers the skills that involve its applicability to the teaching staff, demonstrating itself as a form of gradual teaching, a gradual, noncompulsory and with concise support of the technical area, providing a strong link between the institutions, teacher and student through the virtual learning environment.The Moodle application and construction method presented proved to be effective as a complement to traditional school, with acceptance by the students and teachers, making the teacher more present in the student's life
\end{abstract}

Resumo: A partir da evolução do ensino EAD no Brasil pode-se afirmar que tal prática se encontra consolidada no curso superior. Apesar desta afirmativa, pouco se relata na estrutura básica de ensino bem como sua aplicaçao. Logo, o trabalho objetiva realizar o estudo de caso na aplicação do ensino EAD, de forma complementar ao ensino básico tradicional. A pesquisa abrange as dificuldades que envolvem a sua aplicabilidade ao corpo docente, demonstrando que a inserção da forma de ensino híbrida complementar na educação, aplicada de forma gradual, não obrigatória e com suporte conciso da área técnica, propiciando uma forte ligação entre a instituição, o professor $e$ aluno por meio do ambiente virtual de aprendizagem. O método de aplicação e construção do Moodle apresentado demostrou ser eficaz como complemento do ensino tradicional, com aceitação junto ao corpo de alunos e professores, tornando o professor mais presente na vida do estudante.

\section{Introdução}

O Brasil é um país com extensa área territorial e grandes diferenças culturais em seus diversos estados. A sua extensão territorial e sua diversidade cultural são desafios na 
VII Congresso Brasileiro de Informática na Educação (CBIE 2018)

Anais dos Workshops do VII Congresso Brasileiro de Informática na Educação (WCBIE 2018)

popularização e controle de qualidade do ensino brasileiro. As distâncias entre o aluno e a escola, juntamente com a dificuldade de locomoção, tornam-se para o aluno um desafio diário na construção do seu conhecimento.

No ano de 2018, o governo federal ampliou o programa "internet para todos" com a possibilidade de disponibilizar conexão em áreas de difícil acesso por meio do novo Satélite Geoestacionário de Defesa e Comunicações Estratégicas (SGDC), lançado em 2017, no qual recebeu 3 bilhões em investimentos para sua implementação.

Nessa perspectiva, percebe-se o fomento da chamada EAD (Educação a Distância) que é baseada no construcionismo ${ }^{1}$ com ênfase na interatividade virtual, promovendo o trabalho colaborativo calcado na vontade dos indivíduos envolvidos e, sobretudo, na interação aprendiz-computador-professor-aprendiz ${ }^{2}$, estabelecendo um ciclo que vai evoluindo à medida que se dá a construção do conhecimento. A pesquisa procurou refletir sobre o uso das Novas Tecnologias de Informação e Comunicação (NTICs), mais especificamente na construção do método de aplicação do ambiente virtual de aprendizagem Moodle em uma instituição de ensino federal que se destaca pela sua excelência na formação não somente do aluno, mas um cidadão. A pesquisa procura identificar se há inovação, ruptura ou conservação do status quo. Insere-se em uma preocupação de explicitar os pressupostos pedagógicos que fundamentam esta ação. Portanto o trabalho contempla a análise das dificuldades que envolvem a sua aplicabilidade, bem como quantificar quais instrumentos disponibilizados no AVA, Ambiente Virtual de Aprendizagem, possui maior aceitação no processo da evolução do aluno.

\section{Contexto do Estudo}

Atualmente, vive-se em um mundo de constantes e contínuas transformações em uma acelerada evolução das tecnologias de informação e comunicação, com os espaços de interação humana imensamente ampliados. Isso, por sua vez, potencializa os espaços educativos. Entre as possibilidades acima citadas, tem-se a Comunicação Mediada por Computador - CMC, que pode ocorrer de forma assíncrona (correio eletrônico, lista de discussão, fórum) e de forma síncrona (chat, teleconferência, etc.). Porém, para garantir um ambiente que proporcione real aprendizagem e desenvolvimento dos sujeitos aprendentes, não basta apenas implementar a tecnologia no sistema educacional.

Vive-se na era digital, onde o Ambiente Virtual de Aprendizagem AVA se torna necessário no processo de ensino e aprendizagem. Pelo ponto de vista pedagógico é muito importante que haja interação entre professor e o aluno na construção e desenvolvimento da aprendizagem. Desta forma, o AVA deve proporcionar essa troca de informação, para mostrar ao professor o desenvolvimento do processo de aprendizagem do estudante. Segundo Vygotsky (1998), este acompanhamento refere-se ${ }^{1}$ Cf. Papert (1994) O termo Construcionismo, no uso educacional contemporâneo em geral, remete à doutrina de Piaget enfatizando que o conhecimento
não pode simplesmente ser transmitido ou transferido pronto para uma pessoa. 
VII Congresso Brasileiro de Informática na Educação (CBIE 2018)

Anais dos Workshops do VII Congresso Brasileiro de Informática na Educação (WCBIE 2018)

a Zona de Desenvolvimento Proximal (ZDP) do aluno, onde entende-se o espaço entre o aluno ter habilidade em resolver sozinho a atividade e o espaço onde precisa do auxilio do professor. Desta forma, o estudante evolui em habilidades e amplia a Zona de Desenvolvimento Proximal.

Para Mozzaquatro e Medina (2008), avaliar AVA é uma função árdua, pois está em constante transformação e desenvolvimento. A análise do Ambiente Virtual de Aprendizagem AVA é um tema que vem sendo debatido pelos autores da área da educação, principalmente pelos especialistas em informática na educação, pela relevância que esta ferramenta tem como recurso nas práticas educacionais.

Avaliar a qualidade do ambiente virtual de aprendizagem é, segundo Carvalho Neto (2011), a análise da qualidade deste espaço que perpassa por informações que contém no ambiente e pela usabilidade e funcionalidade do sistema. Segundo o autor o estudo da qualidade do AVA deve ser dividido em dois grupos pela ótica da funcionalidade. $\mathrm{O}$ primeiro grupo está relacionado ao desempenho do próprio sistema. O outro grupo refere-se aos aspectos gerais da usabilidade, ou seja, da forma como o usuário se relaciona com o sistema.

No contexto de AVA, Bassani e Behar (2006, p. 01) comentam que nesses espaços tem-se a possibilidade do acompanhamento da frequência e da produção de cada aluno, uma vez que os ambientes possuem uma base de dados que armazena e pode armazenar a frequência e assiduidade a cada um dos recursos disponíveis no ambiente. Segundo as autoras, o enfoque quantitativo da interação faz referência ao que é possível apresentar de informações quantificáveis, como número de acessos ao ambiente, número de acessos a determinadas atividades, quantidade de trabalhos enviados ou ainda o número de contribuições em determinada ferramenta (Bassani; Behar, 2006, p. 02 -03).

É necessário mudar a perspectiva dos sujeitos que participam no espaço virtual de aprendizagem com a interação. Porém esse processo é gradativo, com algumas atitudes dos estudantes com relação aos recursos e a autonomia.

\section{Ciclo de aprendizagem e Software Educativos}

O E-learning também conhecido por Ensino a Distância ou Educação a Distância (EAD), tornou-se uma tendência, contribuindo com os métodos tradicionais de ensino e apresentando alternativas que ensejam economia de recursos e de tempo na produção de conhecimento. Esse necessita integrar atividades em conjunto com as novas tecnologias de informação e comunicação, de modo que essas sirvam como ferramentas qualitativas e inovadoras, e que tenham a capacidade de instrumentalizar alunos e professores para $o$ desenvolvimento de novas possibilidades de trabalho.

O processo de construção do conhecimento, que acontece na relação do sujeito com outros sujeitos, foi amplamente pesquisado por Jean Piaget que explicou essa construção por intermédio do ciclo Assimilação-Adaptação-Acomodação. Para Papert3 (1980), a importância de enriquecermos os ambientes de aprendizagem onde os sujeitos atuarão e serão capazes de construir os conceitos e ideias reside na qualidade dos conhecimentos lá construídos que impregnam esses ambientes. Apresentou ainda o

${ }^{3}$ Pesquisador Sul Africano, que trabalhou com Piaget. 
termo que é muito utilizado na construção do conhecimento, sob a influência das novas tecnologias de informação e comunicação, denominado construcionismo. Esse é gerado sobre a suposição de que os aprendizes farão melhor descobrindo por si mesmos o conhecimento específico de que necessitam.

O ensino pode utilizar ambientes de suporte para Educação a Distância, os quais constituem um espaço virtual organizado que pode facilitar as interações por meio de Chat, Fórum ou Grupo de Discussão, Correio, Portfólio e outras. Por outro lado, a bibliografia especializada enfatiza que o computador é uma ferramenta adequada para proporcionar a construção do conhecimento mediante a utilização de softwares educativos abertos, software aplicativo na educação ou com software utilitário para educação.

\subsection{Ambiente Virtual de Aprendizagem - Moodle}

Os ambientes virtuais de aprendizagem, conhecidos como AVA, são ferramentas que possuem o objetivo de auxiliar a construção de cursos ou treinamentos com a utilização da web. Logo, essas ferramentas pretendem auxiliar o professor a gerenciar o conteúdo a ser disponibilizado aos alunos, bem como fomentar o controle de acessos e conteúdo de seus alunos ao sistema. A EAD é uma possibilidade concreta na promoção da democratização do saber, com seus benefícios que podem ser avaliadores com base em critérios primordialmente técnicos, sociais e econômicos. Os enfoques de aprendizagem aberta e métodos de aprendizagem a distância, exercem impacto sobre o campo educacional, sendo particularmente apropriados ou eficientes e suscitando concepções de geração, transmissão e aquisição de conhecimento.

O Modular Object-Oriented Dynamic Learning Environment (MOODLE), é um sistema de administração de atividades educacionais destinado à criação de comunidades online, em ambientes virtuais voltados para a aprendizagem colaborativa. Permite, de modo simplificado, a um estudante ou a um professor integrar-se, estudando ou lecionando, em um curso online à sua escolha. Seu foco é disponibilizar aos educadores as melhores ferramentas para gerenciar e promover a aprendizagem.

Dentre os ambientes virtuais de aprendizagem existente, tratamos mais especificamente do Moodle, por ser um software consolidado e de expressiva aceitação pelos usuários. Esse necessita de uma ergonomia adequada; como aprendiz, não pode dispensar a pedagogia; e, como leitor, necessita da comunicação com o meio que viabiliza a aprendizagem.

\section{Caminhos da Pesquisa}

A dialética é a arte da discussão logo se apresentou como a melhor opção metodológica para organização desta pesquisa, considerando que o foco deste trabalho era adentrar o âmbito da aplicabilidade do uso das Novas Tecnologias de Informação e Comunicação (NTIC), mais especificamente no AVA - Moodle - a partir da experiência em uma Instituição de Ensino federal.

A pesquisa, foi realizada por meio de observação direta, pesquisa bibliográfica institucional e perguntas de múltipla escolha, aplicada aos professores que fazem o uso do ambiente Moodle como complemento da sala de aula. 
VII Congresso Brasileiro de Informática na Educação (CBIE 2018)

Anais dos Workshops do VII Congresso Brasileiro de Informática na Educação (WCBIE 2018)

\subsection{O Lócus da Pesquisa}

O Colégio Militar de Porto Alegre (CMPA) está entre os mais antigos e tradicionais do sistema e contém peculiaridades que o distinguem dos outros colégios, possivelmente, devido a fatores como: o seu processo histórico, considerado o colégio dos presidentes bem como o seu significado com a comunidade local e história gaúcha.

O CMPA, trata-se de uma Instituição com mais de 100 anos de existência. O ingresso se dá a partir do $6^{\circ}$ Ano do Ensino Fundamental e no $1^{\circ}$ Ano do Ensino Médio, através de concurso público aberto à toda a população. Seu diferencial educacional consiste no fato de possuir uma proposta pedagógica que almeja a educação integral. Cujo objetivo é não só proporcionar uma sólida base em conteúdos disciplinares, mas também preparar o aluno para a vida cidadã.

A opção por essa instituição se deve ao fato de que ela se destaca por sua organização e busca incessante em unir a tradição ao uso racional das novas tecnologias. Por conseguinte, visamos estudar a aplicabilidade e funcionalidade do ambiente virtual de aprendizagem - Modular Object-Oriented Dynamic Learning Environment (MOODLE) -, no contexto da escola, a partir do olhar dos professores e gestores.

\subsection{Estrutura da Pesquisa}

Durante a pesquisa, foi realizado um levantamento criterioso dos pressupostos que embasam a implantação e utilização do Moodle na prática cotidiana dos sujeitos. No decorrer da pesquisa foi necessário revisar os materiais escritos (projetos de implementação da capacitação de professores, planejamentos de ações docentes, entre outros); conhecer os espaços sócio-político-culturais em que se dá a implantação e implementação do uso das NTIC; realizar ampla revisão teórica sobre concepções dos processos do ensinar e do aprender na instituição de Ensino. Na figura abaixo, é possível verificar as fases no desenvolvimento da pesquisa:

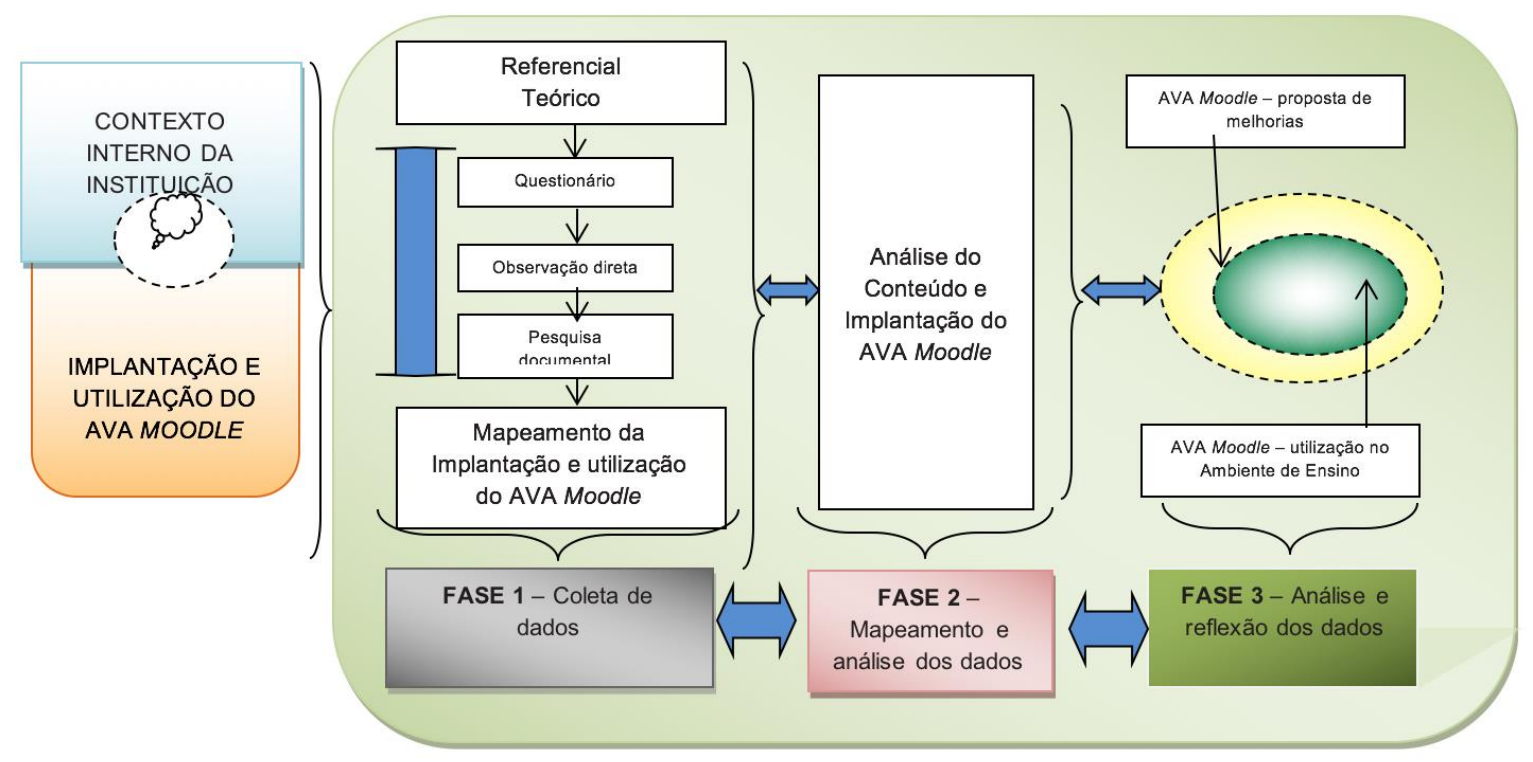

Figura 1. Organização da Pesquisa Fonte: Imagem criado pelos autores. 
Para melhor compreender as diferentes etapas procurou-se seguir, não de forma linear ou estanque, as três fases (Figura 1), da organização da pesquisa que determinou a estratégia realizada para a coleta de dados visando posterior análise, para $o$ processamento dos elementos coletados na pesquisa. Esse processo propiciou retornar informações relevantes ao material levantado com o questionário e revisão bibliográfica.

\section{O Moodle e Sua Implantação}

A implementação do Moodle como ferramenta de Ambiente Virtual de Aprendizagem na instituição de Ensino, ocorreu a partir da necessidade dos professores em utilizar ferramentas virtuais de aprendizagem

A implantação do Moodle ocorreu desde a sua concepção de forma não obrigatória ao corpo de professores, cabendo ao professor a escolha da aplicação e suas respectivas ferramentas como complemento da sala de aula. $\mathrm{O}$ fato da não obrigatoriedade, ocorreu devido a alguns professores não estarem familiarizados de forma plena com as ferramentas digitais.

A partir da sua implantação, os professores da instituição obtiveram em caráter não obrigatório, cursos para a utilização da ferramenta e suporte na gestão de suas disciplinas, de acordo com as suas necessidades, a partir do corpo técnico institucional de forma contínua e presencial. Os professores além de obterem as capacitações sempre que solicitado, possuem integralmente o suporte tecnológico de forma presencial para sanar eventuais dúvidas na construção de suas salas virtuais.

Os professores que fazem o uso da ferramenta Moodle como complemento em sala de aula, o fazem de forma complementar, disponibilizando aos alunos vídeos, chat, artigos, lista de exercícios, jogos e avaliações on-line. A ferramenta possibilitou que o custo operacional das disciplinas que necessitavam de impressões fosse substituído, quando possível, por material digital.

\subsection{Análise do Questionário Aplicado aos Professores}

O questionário aplicado aos professores que fazem o uso da ferramenta Moodle por no mínimo 2 anos, em sua maioria com idade superior a 50 anos, com formação mínima de mestrado em sua área específica bem como dedicação exclusiva ao ensino. A partir do conceito do construcionismo no uso educacional contemporâneo, e a aplicação do conhecimento construído com base na interação mútua entre o professor e aluno, utilizando o Moodle como meio de comunicação complementar a tradicional sala de aula. A pesquisa for realizada nas categorias Interatividade, Flexibilidade, Escalabilidade, Estandarização e Usabilidade a partir de um questionamento inicial demostrado abaixo:

\section{Qual a sua opinião como educador na utilização do Moodle como ferramenta} de extensão ao ensino?

Os professores relatam que o Moodle potencializa as aulas presenciais de forma dinâmica havendo maior interação entre os alunos e o educador, pois o mundo virtual faz parte da natureza do aluno digital. Os professores destacam que com o ambiente 
VII Congresso Brasileiro de Informática na Educação (CBIE 2018)

Anais dos Workshops do VII Congresso Brasileiro de Informática na Educação (WCBIE 2018)

virtual é um local seguro para a construção do conhecimento sem propagandas ou elementos impróprios, possibilitando em muitos casos o acompanhamento, orientação bem como o atendimento individualizado a partir de mensagem privadas, que muitas vezes não é realizado em sala de aula, seja por falta de tempo ou vergonha do aluno perante aos demais colegas. A interação, segurança, flexibilidade, acompanhamento e a possibilidade de complementar o conhecimento por meio de ferramentas digitais, são os principais fatores destacados na pesquisa, com destaque na redução do número de reprovações após sua aplicação.

2.Quais foram as maiores dificuldades na utilização do Moodle? As dificuldades foram superadas?

Os professores não relataram maiores dificuldades de utilização do ambiente virtual, salientando que os colegas e a área técnica sempre à disposição foram de fundamental importância para a utilização da ferramenta bem como a sua curva de aprendizagem. Os professores relatam que o Moodle é um aprendizado gradual, que a partir do conhecimento e a troca de informações entre colegas foi possível compreender todas as ferramentas disponíveis na plataforma. Os professores relatam que as maiores dificuldades se encontram na infraestrutura tecnológica da escola, na disponibilidade de computadores e internet para a utilização em ambiente de trabalho e não o ambiente virtual em si. As poucas dificuldades relatadas na utilização da ferramenta foram sanadas rapidamente com a maior utilização da ferramenta ou suporte do corpo técnico.

3.Como você vê os aspectos e a possibilidade do uso de sistema educacional em EaD (de acordo com A ISO/IEC 9126-1)?

A resolução se dá a partir de um questionário de múltipla escolha. Os gráficos, correspondem à média das respostas obtidas durante a pesquisa, de acordo com a sua respectiva legenda em suas diferentes categorias.

\section{Interatividade}

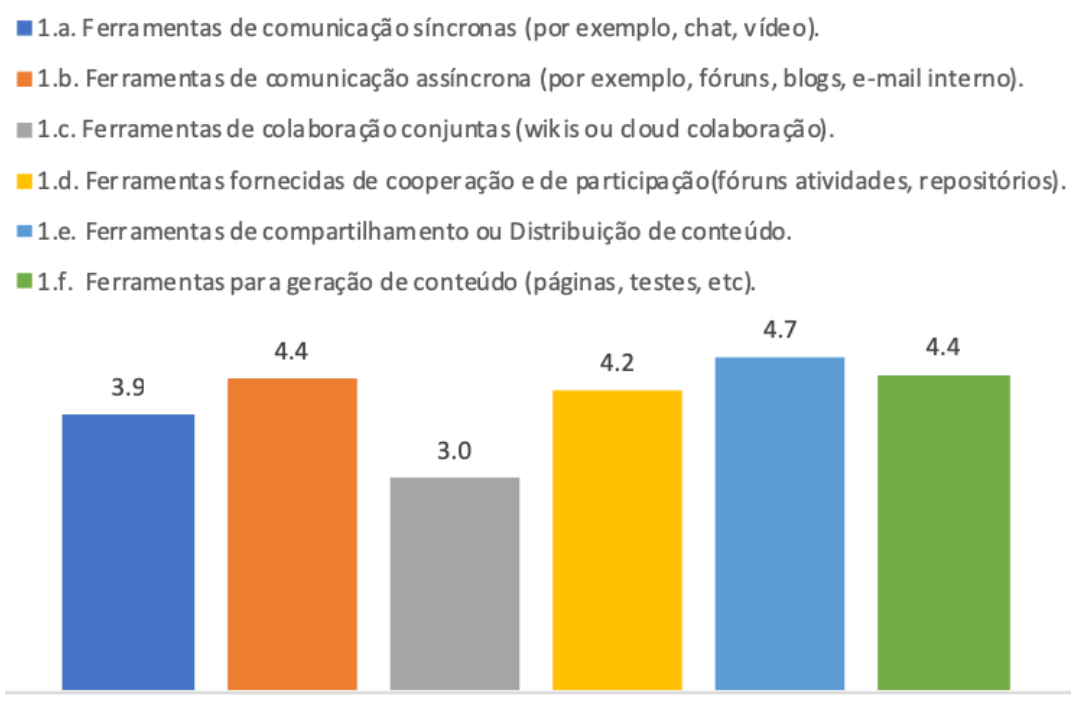

[0] Não afe ta. [1] Afeta muito pouco. [2] Pouco afeta. [3] Indiferente. [4] Afeta. [5] Afeta muito.

Gráfico 1. Análise do Questionário de Interatividade 
VII Congresso Brasileiro de Informática na Educação (CBIE 2018)

Anais dos Workshops do VII Congresso Brasileiro de Informática na Educação (WCBIE 2018)

2.Flexibilidade - 3.Escalabilidade - 4. Estandarização
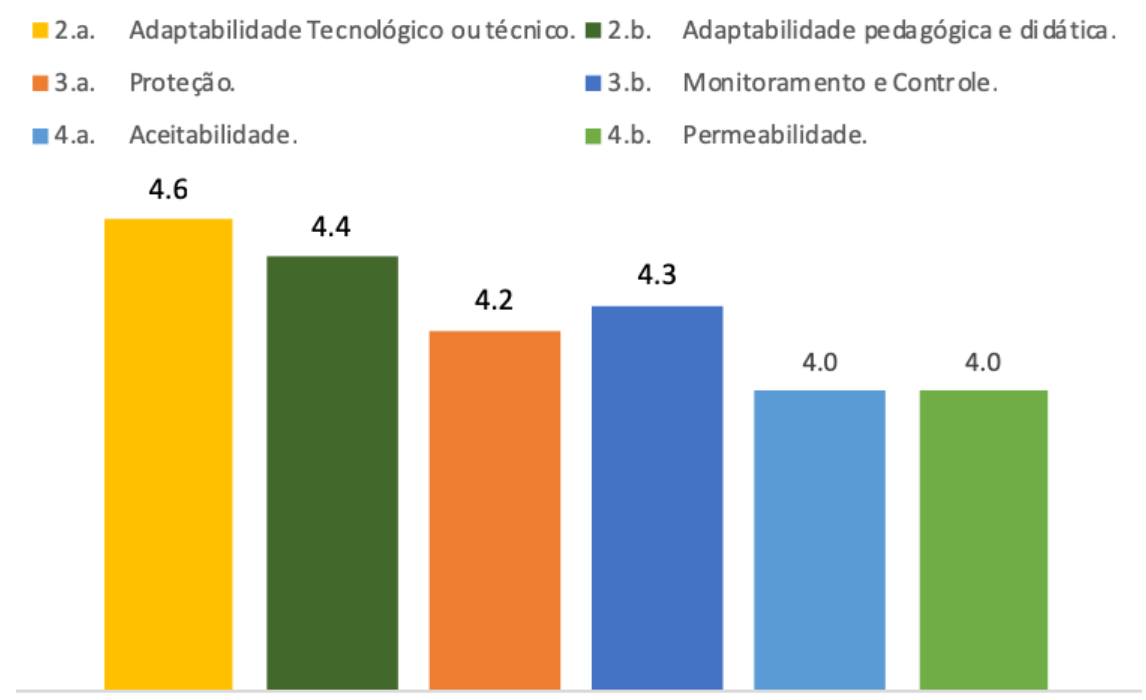

[0] Não afeta. [1] Afeta muito pouco. [2] Pouco afeta. [3] Indiferente. [4] Afeta. [5] Afeta muito.

\section{Gráfico 2. Análise do Questionário de Flexibilidade, Escalabilidade e Estandarização}

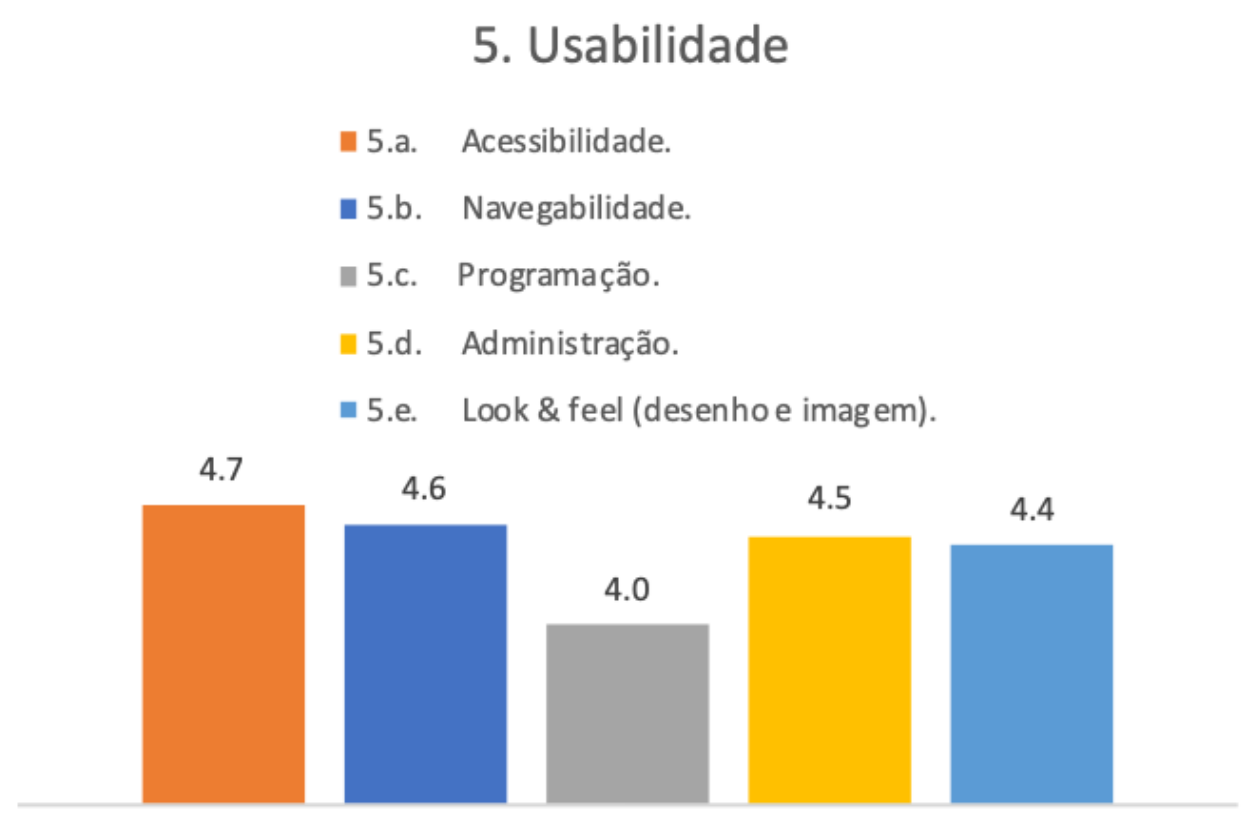

[0] Não afeta. [1] Afeta muito pouco. [2] Pouco afeta. [3] Indiferente. [4] Afeta. [5] Afeta muito.

\section{Gráfico 3: Análise do Questionário de Usabilidade}


VII Congresso Brasileiro de Informática na Educação (CBIE 2018)

Anais dos Workshops do VII Congresso Brasileiro de Informática na Educação (WCBIE 2018)

\section{Funcionalidade - 7. Ubiquidade - 8. Persuabilidade Geral}
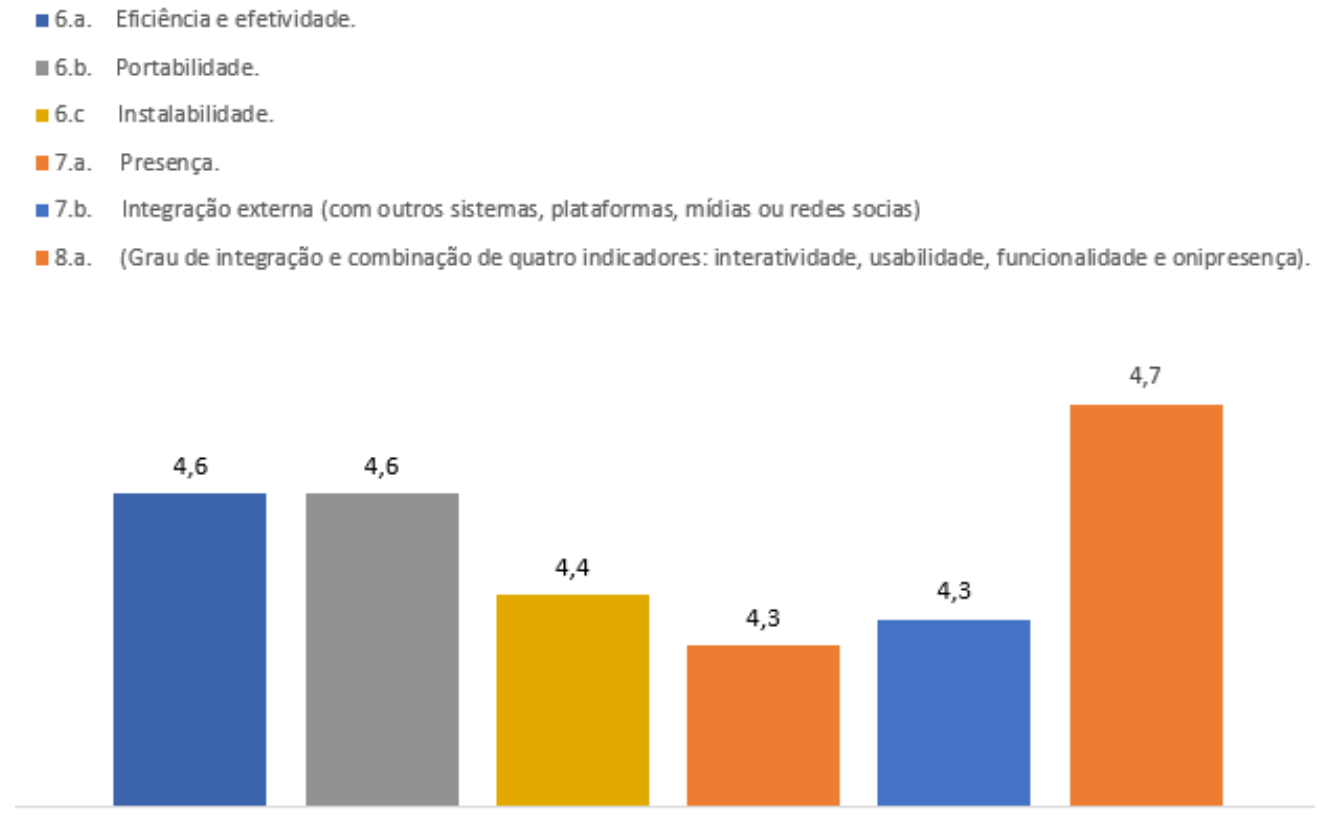

[0] Não afeta. [1] Afeta muito pouco. [2] Pouco afeta. [3] Indiferente. [4] Afeta. [5] Afeta muito.

\section{Gráfico 4: Análise do Questionário de Funcionalidade, Ubiquidade e Persuabilidade Geral}

A partir da análise dos Gráficos, é possível verificar que a interatividade na utilização do Moodle como extensão da sala de aula, proporcionou positivamente entre alunos e professores o uso de ferramentas educacionais como suporte ao ensino e aprendizagem. A ferramenta Wikis foi considerada indiferente devido ao fato de os professores não fazerem o uso no ambiente. A partir da análise do Gráfico 2, devemos destacar que a flexibilidade no uso das ferramentas e a estandarização do ambiente, foi de fundamental importância no desenvolvimento do material e desenvolvimento pedagógico do aluno. Um fato muito destacado pelos professores durante a pesquisa, relaciona-se ao fato que o ambiente é considerado seguro e controlado pelo professor, sem propagandas ou desvio de atenção do aluno durante a sua utilização, assim evitando o uso equivocado de ferramentas computacionais na construção do conhecimento.

As categorias que contemplam a usabilidade, funcionalidade, ubiquidade e persuabilidade presentes nos gráficos 3 e 4 se mostraram extremamente contempladas durante a utilização da ferramenta Moodle, por tratar-se de um ambiente conhecido por todos, a internet, não trazendo quaisquer dificuldades durante a sua utilização, atribuído ao constante suporte da equipe técnica, que por muitas vezes, abstraia eventuais dificuldade na integração com outros sistemas.

\section{Considerações Finais}

A implantação do Moodle desde a sua concepção de forma não obrigatória ao corpo de professores, cabendo ao professor a escolha da aplicação e suas respectivas ferramentas como complemento da sala de aula, foi de fundamental importância para o 
VII Congresso Brasileiro de Informática na Educação (CBIE 2018)

Anais dos Workshops do VII Congresso Brasileiro de Informática na Educação (WCBIE 2018)

seu sucesso, pois não é apenas a ferramenta que contempla o aprendizado e sim a união do professor para com os alunos, a partir do uso de ferramentas educacionais digitais. Outro ponto a ser destacado para o sucesso de sua implantação, refere-se aos treinamentos oferecidos bem como o permanente suporte da equipe técnica $\mathrm{e}$ pedagógica, a partir da construção do ambiente estendendo-se ao apoio pedagógico em sua utilização.

A partir da construção constante do ambiente e sua inserção em sala de aula de forma gradual, fez com que o aluno aceitasse a sua utilização sem quaisquer barreiras, e a partir deste ponto, o próprio aluno solicitava ao professor a inserção de materiais interativos como um roteiro de estudos no decorrer do ano. A partir desta interação, fez com que o aluno se tornasse o protagonista da construção do seu conhecimento e não mais um simples espectador, pois o ambiente proporcionou não somente a interação mas a ligação entre o mundo analógico, no qual o professor vivenciou durante a sua formação com este "novo" complemento de ensino e aprendizagem que faz parte da genética do aluno digital.

\section{Referências}

Bassani, P. S Behar Patrícia Alejandra. Análise das interações em ambientes virtuais de aprendizagem: uma possibilidade para avaliação da aprendizagem em EAD. Renote Revista Novas Tecnologias na Educação, Porto Alegre: Cinted/UFRGS, v. 4, n. 1, p. 01-10, jul. 2006. Disponível em: Acesso em: 20 jun. 2018.

Carvalho N., S. Características Para Avaliação de Qualidade em Ambientes Virtuais de Aprendizagem. São Paulo: [s.n.], 2011. Disponível em: $<$ http://www.abed.org.br/congresso2011/cd/193.pdf>. Acesso em: 18 Jun 2018. Knuth, D. E. (1984), The TeXbook, Addison Wesley, $15^{\text {th }}$ edition.

Fontes, L; Uma Ontologia de Apoio à Participação Efetiva de Alunos em AVAs, Revista Informática na Educação, Porto Alegre:Cinted/UFRGS,v.20 n.3, p. 01-17, dez. 2017.

Disponível em:http://seer.ufrgs.br/index.php/InfEducTeoriaPratica/article/view/79727/47123 Acesso em: 26 Jul 2018.

Moodle (2018). In: Moodle: o software de código aberto para aprendizado colaborativo. Disponível em: . Acesso em: 20 jun. 2018.

Mozzaquatro, P. M.; Medina R. D. Avaliação do Ambiente Virtual de Aprendizagem Moodle sob Diferentes Visões: aspectos a considerar. Revista Novas Tecnologias na Educação (RENOTE). v. 6, n. 1, 2008. Disponível em: $<$ http://seer.ufrgs.br/renote/article/view/14508 >. Acesso em: 18 Jun 2018.

Papert, Seymour M. Logo: Computadores e Educação. São Paulo, Editora, Brasiliense, 1985 (edição original EUA 1980).

Piaget, J. A equilibração das estruturas cognitivas. Rio de janeiro: Zahar Editores, 1976.

Vygotsky, L.S. A Formação Social da Mente. 6. Ed. São Paulo: Martins Fontes, 1998.

Vygotsky, L. S. A formação social da mente: o desenvolvimento dos processos psicológicos superiores. [Trad. José Cipolla Neto et al. 6. ed., São Paulo: Martins Fontes, 2000. 